\title{
Research Progress of TXNIP as a Tumor Suppressor Gene Participating in the Metabolic Reprogramming and Oxidative Stress of Cancer Cells in Various Cancers
}

\author{
Yiting Chen ${ }^{1,2}$, Jieling Ning $^{2}$, Wenjie Cao ${ }^{2}$, Shuanglian Wang $^{3}$, Tao $\mathrm{Du}^{3}$, Jiahui Jiang ${ }^{3}$, \\ Xueping Feng ${ }^{1 *}$ and Bin Zhang ${ }^{2 *}$ \\ ${ }^{1}$ Department of Oncology and Institute of Medical Sciences, National Clinical Research Center for Geriatric Disorders, \\ Xiangya Hospital, Central South University, Changsha, China, ${ }^{2}$ Department of Histology and Embryology, Xiangya School of \\ Medicine, Central South University, Changsha, China, ${ }^{3}$ Institute of Medical Sciences, Xiangya Hospital, Central South \\ University, Changsha, China
}

OPEN ACCESS

Edited by:

Suzie Chen,

Rutgers, The State University of New

Jersey, United States

Reviewed by:

Hiroshi Masutani,

Tenri Health Care University, Japan

Soichiro Yamamura,

University of California, San Francisco,

United States

*Correspondence:

Xueping Feng

xuepfeng@csu.edu.cn;

fxp1029@aliyun.com

Bin Zhang

zhangbin@csu.edu.cn

Specialty section: This article was submitted to Cancer Molecular Targets and Therapeutics,

a section of the journal

Frontiers in Oncology

Received: 01 June 2020 Accepted: 18 August 2020 Published: 21 October 2020

Citation: Chen Y, Ning J, Cao W, Wang S, Du T, Jiang J, Feng $X$ and Zhang B (2020) Research Progress of TXNIP as a Tumor Suppressor Gene Participating in the Metabolic Reprogramming and

Oxidative Stress of Cancer Cells in Various Cancers.

Front. Oncol. 10:568574. doi: 10.3389/fonc.2020.568574
Thioredoxin-interacting protein (TXNIP) is a thioredoxin-binding protein that can mediate oxidative stress, inhibit cell proliferation, and induce apoptosis by inhibiting the function of the thioredoxin system. TXNIP is important because of its wide range of functions in cardiovascular diseases, neurodegenerative diseases, cancer, diabetes, and other diseases. Increasing evidence has shown that TXNIP expression is low in tumors and that it may act as a tumor suppressor in various cancer types such as hepatocarcinoma, breast cancer, and lung cancer. TXNIP is known to inhibit the proliferation of breast cancer cells by affecting metabolic reprogramming and can affect the invasion and migration of breast cancer cells through the TXNIP-HIF1 $\alpha$-TWIST signaling axis. TXNIP can also prevent the occurrence of bladder cancer by inhibiting the activation of ERK, which inhibits apoptosis in bladder cancer cells. In this review, we find that TXNIP can be regulated by binding to transcription factors or other binding proteins and can also be downregulated by epigenetic changes or miRNA. In addition, we also summarize emerging insights on TXNIP expression and its functional role in different kinds of cancers, as well as clarify its participation in metabolic reprogramming and oxidative stress in cancer cells, wherein it acts as a putative tumor suppressor gene to inhibit the proliferation, invasion, and migration of different tumor cells as well as promote apoptosis in these cells. TXNIP may therefore be of basic and clinical significance for finding novel molecular targets that can facilitate the diagnosis and treatment of malignant tumors.

Keywords: TXNIP (thioredoxin interacting protein), cancer, oxidative stress, research progress, clinical significance

\section{INTRODUCTION}

Cancers are chronic diseases that pose serious threats to human health and have increasing incidence rates worldwide. The burden of cancers is increasing relentlessly due to their huge economic and human costs. At present, there are many treatments for malignant tumors, such as surgery, chemotherapy, radiation therapy, and immunotherapy. However, although great progress has been achieved in the treatment of malignant tumors, the precise cause of the disease is poorly understood, which has become a major limiting factor in improving the prognosis of patients. 
As a result of increased research on genomics and epigenetics, it is now anticipated that gene-targeted therapies may be effective in preventing the occurrence and development of human malignant tumors. Therefore, the search for new target genes is of particular significance for the development of cancer treatments. Thioredoxin-interacting protein (TXNIP), a $50-\mathrm{kDa}$ protein (1), is also known as thioredoxin-binding protein 2 (TBP-2) (2) or vitamin D3 upregulated protein 1 (VDUP-1) (3). The gene encoding TXNIP is located in regions 1q2122 of human chromosome 1 and is about 4,174 bp in length, containing 8 exons (4). The TXNIP gene is normally found in the nucleus but can shuttle into the mitochondria under certain conditions (5). TXNIP was first identified in 1995 as a gene that is upregulated in HL-60 cells treated with vitamin D3 (6). As a negative regulator of thioredoxin (TRX) (7), a major redoxregulating molecule, TXNIP participates in regulating the cellular redox status. Oxidative stress caused by the excessive production or accumulation of reactive oxygen species (ROS) is known to be related to cancer pathology and cancer treatment. TXNIP is important for regulating mitochondrial function, inducing apoptosis, and inhibiting growth and metastasis; in addition, it also plays roles in the development of natural killer cells, promoting cell-cycle arrest and regulating glucose metabolism and inflammatory signaling $(8-10)$. TXNIP belongs to the $\alpha-$ arrestin protein family (11), the members of which have two domains, namely, SH3 and PPxY (12); through these domains, TXNIP can interact with other proteins to perform different biological roles.

\section{CANCERS OF ENDOCRINE GLANDS AND GENITAL TRACT (TABLE 1) \\ TXNIP and Breast Cancer}

Breast cancer arises from breast epithelial tissue. Because TXNIP is an effective tumor suppressor, it is often found to be expressed at low levels in different kinds of tumors (25); in particular,

\footnotetext{
Abbreviations: TRX, thioredoxin; TXNIP, thioredoxin interacting protein; SH3, src homology domain 3; EMT, epithelial mesenchymal transition; TNBCs, triple negative breast cancers; JAK-STAT, janus kinase/signal transducers and activators of transcription; PTC, papillary thyroid cancer; RCC, renal cell carcinoma; CCRCC, clear cell renal cell carcinoma; BC, bladder cancer; PCA, prostate cancer; p27, tumor protein 27; GLUT1, glucose transporter type 1; HIF1 $\alpha$, hypoxiainducible factor- $1 \alpha$; MAPK, mitogen-activated protein kinase; UHRF1, ubiquitinlike ringfinger domains 1 ; TGF- $\beta$, transforming growth factor- $\beta$; HDAC1, histone deacetylase 1; AMPK, adenosine 5-monophosphate (AMP)-activated protein kinase; cRAPGEF5, circRNA RAPGEF5; ERK, extracellular regulated protein kinases; GLS 1, glutaminase 1; ChREBP, response element binding protein; ChoRE, carbohydrate response element; RNF2, nuclear factor E2-related factor 2; HCC, hepatocellular carcinoma; PDAC, pancreatic ductal adenocarcinoma; EAC, esophageal adenocarcinoma; ChREBP, the carbohydrate response element binding protein; ROS, reactive oxygen species; HIF1, hypoxia-inducible factor; Fbw 7, F-box and WD repeat domain-containing7; TNF- $\alpha$, TumorNecrosisFactor$\alpha$; NF- $\kappa$, nuclear factor kappa-B; COX-2, cyclooxygenase-2; NSCLC, nonsmall cell lung cancer; CDDP, cisplatin; AML, acute myeloid leukemia; PRC2, polycomb repressive complex 2; EZH2, enhancer of zeste homolog 2; OS, osteosarcoma; PI3K, phosphatidylinositide 3-kinases; PKB, Akt-protein kinaseB; TKIS, tyrosine kinase inhibitors; ASK1, apoptosis signal-regulating kinase 1; TRAF6-TNF, receptor associated factor 6; JQ1, an Inhibitor of BET bromodomain; PRMT5, protein arginine methyltransferase 5; HR-NB, high risk neuroblastoma; $\mathrm{NB}$, neuroblastoma.
}

TXNIP expression levels in human breast cancer MCF-7 cells are markedly decreased $(26,27)$. It has been well-documented that TXNIP expression is positively associated with the loss of tumor differentiation and that TXNIP levels gradually decrease as tumors advance in animal models. TXNIP levels have been found to recover immediately after treatment with histone deacetylase inhibitors, suggesting that histone deacetylation may influence TXNIP expression. TXNIP gene knockout can promote the proliferation of breast cancer cells, which is accompanied by decreased p27 expression and increased glucose transporter type 1 (GLUT1) levels (13). Most cases of mortality due to breast cancer involve distant metastases (28). The epithelial to mesenchymal transition (EMT) is a key process promoting tumor metastasis, wherein the levels of the adhesion protein Ecadherin decrease (29). Hypoxia-inducible factor $1 \alpha(\mathrm{HIF}-1 \alpha)$ is involved in the metastasis and progression of various cancers and is closely related to the failure of various cancer treatments and the resulting patient mortality (30). TWIST and HIF- $1 \alpha$ are two key inducers of EMT in cancer cells, with the former being a downstream effector of HIF-1 $\alpha$. The oncogene miR-373 is known to promote tumor migration and invasion in breast cancer, although the mechanism is poorly understood (31-34). It has, however, been shown that miR-373 decreases the expression of TXNIP by interacting with the 3/ untranslated region (UTR) of TXNIP (Figure 1a) to reduce TXNIP-dependent ROS, activate EMT, and thereby promote tumor migration and invasion. It has been postulated that the activation of the miR-373-TXNIPHIF1 $\alpha$-TWIST signaling axis is related to the poor prognosis of breast cancer patients (Figure 2A) and that TXNIP levels may be a potential prognostic biomarker for breast cancer (14). Patients with triple negative breast cancer (TNBC) have lower survival rates, higher rates of recurrence, and greater changes of metastasis than those with other types of breast cancer. Previous studies have proven that the transcription factor c-myc drives glucose metabolism in TNBCs. One possible mechanism of this process is that c-myc competes with the related transcription factor MondoA to interact with the E-box-containing region in the TXNIP promoter, so as to reduce the expression of TXNIP (Figure 1b). This results in an enhancement of aerobic glycolysis in the TNBC cells, thereby providing more ATP to fuel the growth and proliferation of TNBC cells, making the treatment of TNBC more difficult. Researchers have also shown that low level of TXNIP expression is related to poor prognosis in patients with breast cancer, and so, TXNIP may be of great importance in providing new targets for the treatment of patients with TNBC (15).

\section{TXNIP and Thyroid Cancer}

Thyroid cancer arises from the follicles or thyroid cells adjacent to the follicles. Despite the decrease in thyroid cancer-related morbidity in recent decades (35), the incidence rate of thyroid cancer is increasing rapidly and thyroid cancer represents a considerable medical burden (36-38). Surgery, radiation therapy, and chemotherapy are common treatments for thyroid cancer; however, the prognosis for patients with thyroid cancer remains poor $(39,40)$. It has been shown that TXNIP overexpression decreases the growth of HTh74 cells and inhibits glucose uptake. 
TABLE 1 | TXNIP expression in cancers of the endocrine glands and genital tracts.

\begin{tabular}{|c|c|c|c|c|c|}
\hline Tumor type & $\begin{array}{l}\text { Upstream or } \\
\text { downstream } \\
\text { molecular }\end{array}$ & Significance & $\begin{array}{l}\text { TXNIP } \\
\text { expression }\end{array}$ & Samples & References \\
\hline Breast cancer & p27 and GLUT 1 & Promote the growth of breast cancer cells in vitro and in vivo & Down & Cell lines, tissue & (13) \\
\hline Breast cancer & $\begin{array}{l}\operatorname{miR}-373 \text { and } \\
\text { HIF1 } \alpha\end{array}$ & miR-373 drives the transformation and metastasis of breast cancer & Down & $\begin{array}{l}\text { Cell lines, tissue, } \\
\text { animal }\end{array}$ & $(14)$ \\
\hline Breast cancer & c-Myc & $\begin{array}{l}\text { C-myc competes with related transcription factor MondoA and } \\
\text { drives glucose metabolism }\end{array}$ & Down & Cell lines & $(15)$ \\
\hline Thyroid cancer & - & Expression correlates with metastatic properties & Down & Cell lines, animal & $(16)$ \\
\hline PTC & - & $\begin{array}{l}\text { The expression of TXNIP in PTC tissues was lower than that in } \\
\text { normal thyroid tissues }\end{array}$ & Down & tissue & $(17)$ \\
\hline Renal cancer & UHRF1 & $\begin{array}{l}\text { UHRF1 can recruit HDAC1 to the TXNIP's promoter and mediate } \\
\text { the deacetylation of histone H3K9 }\end{array}$ & Down & Cell lines, tissue & $(18)$ \\
\hline Renal cancer & cRAPGEF5 & $\begin{array}{l}\text { CRAPGEF5 targets miR-27a-3p to promote the proliferation and } \\
\text { migration of RCC }\end{array}$ & Down & Cell lines, tissue & $(19)$ \\
\hline Bladder cancer & ERK & Improve disease-specific survival & Down & $\begin{array}{l}\text { Cell lines, tissue, } \\
\text { animal }\end{array}$ & $(20)$ \\
\hline Prostate cancer & c-Myc and GLS 1 & C-myc activates glutamine 1 (GLS 1) to accelerate the proliferation & Down & Cell lines, tissue & $(21)$ \\
\hline Prostate cancer & NRF2 & $\begin{array}{l}\text { RNF2 binds to TXNIP's promoter to increase apoptosis and inhibit } \\
\text { proliferation }\end{array}$ & Down & $\begin{array}{l}\text { Cell lines, tissue, } \\
\text { animal }\end{array}$ & $(22)$ \\
\hline Cervical cancer & MondoA & $\begin{array}{l}\text { MondoA overexpression inhibited cell proliferation, migration, and } \\
\text { invasion }\end{array}$ & Down & Cell lines & $(23)$ \\
\hline $\begin{array}{l}\text { Endometrial } \\
\text { cancer }\end{array}$ & Vitamin D3 & $\begin{array}{l}\text { VitaminD3 can increase the expression of TXNIP to inhibit the } \\
\text { proliferation of endometrial cancer cells }\end{array}$ & Down & Cell lines & (24) \\
\hline
\end{tabular}

p27, tumor protein 27; GLUT1, Glucose transporter type 1; HIF1 $\alpha$, hypoxia-inducible factor-1 $\alpha$; UHRF1, ubiquitin-like ringfinger domains 1; cRAPGEF5, CircRNA RAPGEF5; ERK, extracellular regulated protein kinases; GLS 1, Glutaminase 1; RNF2, nuclear factor E2-related factor 2.

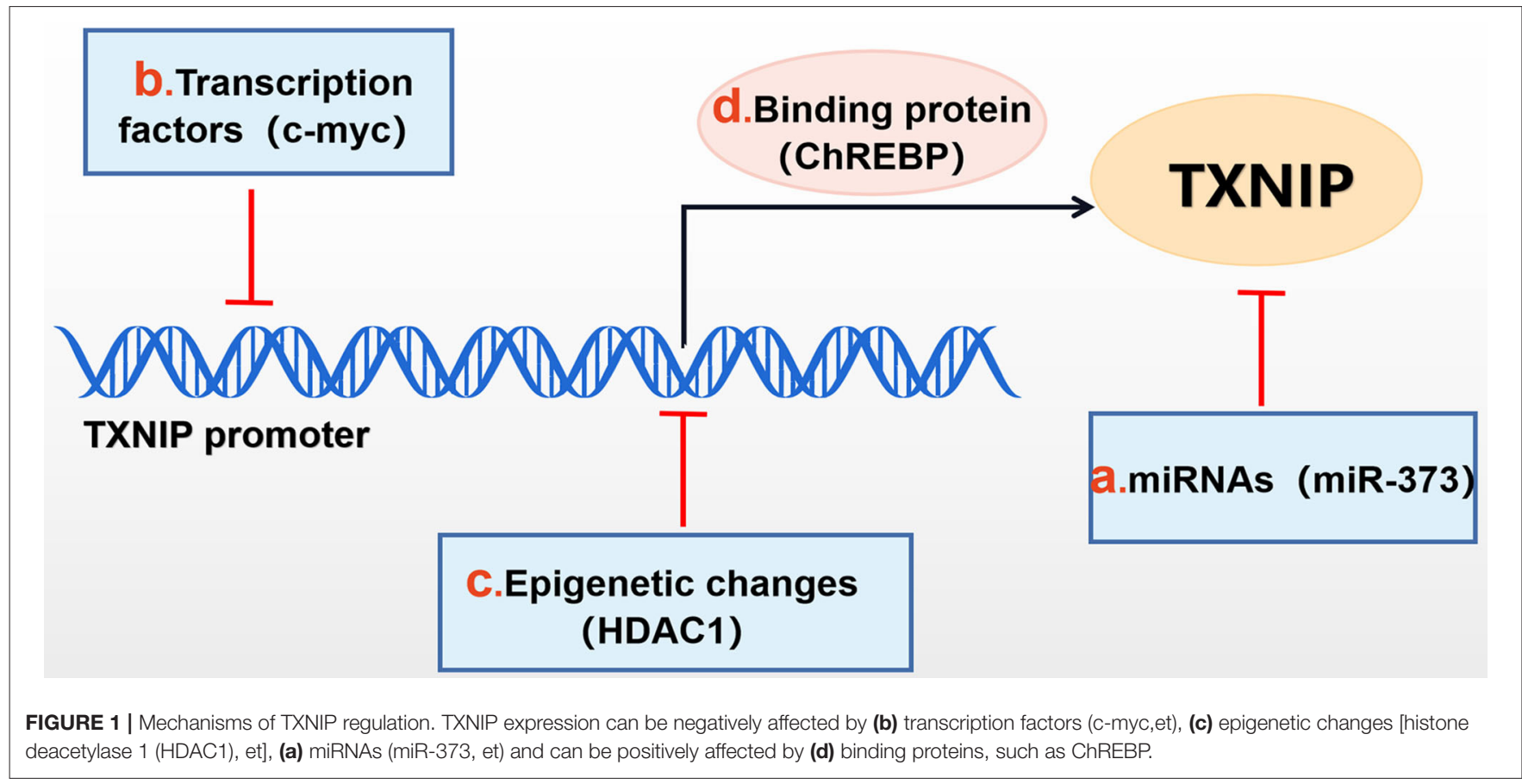

It has also been shown that TXNIP overexpression in T238 cells inhibits tumor growth and decreases metastasis in a mouse model of in situ thyroid cancer (16). Papillary thyroid cancer (PTC), which causes serious harm to human health, accounts for $80-90 \%$ of all thyroid cancers (41), and its incidence rate is increasing year by year. The pathogenesis of PTC is related to the dysfunction of many oncogenes, apoptosis-related genes, and tumor suppressor genes. With the development of proteomics 


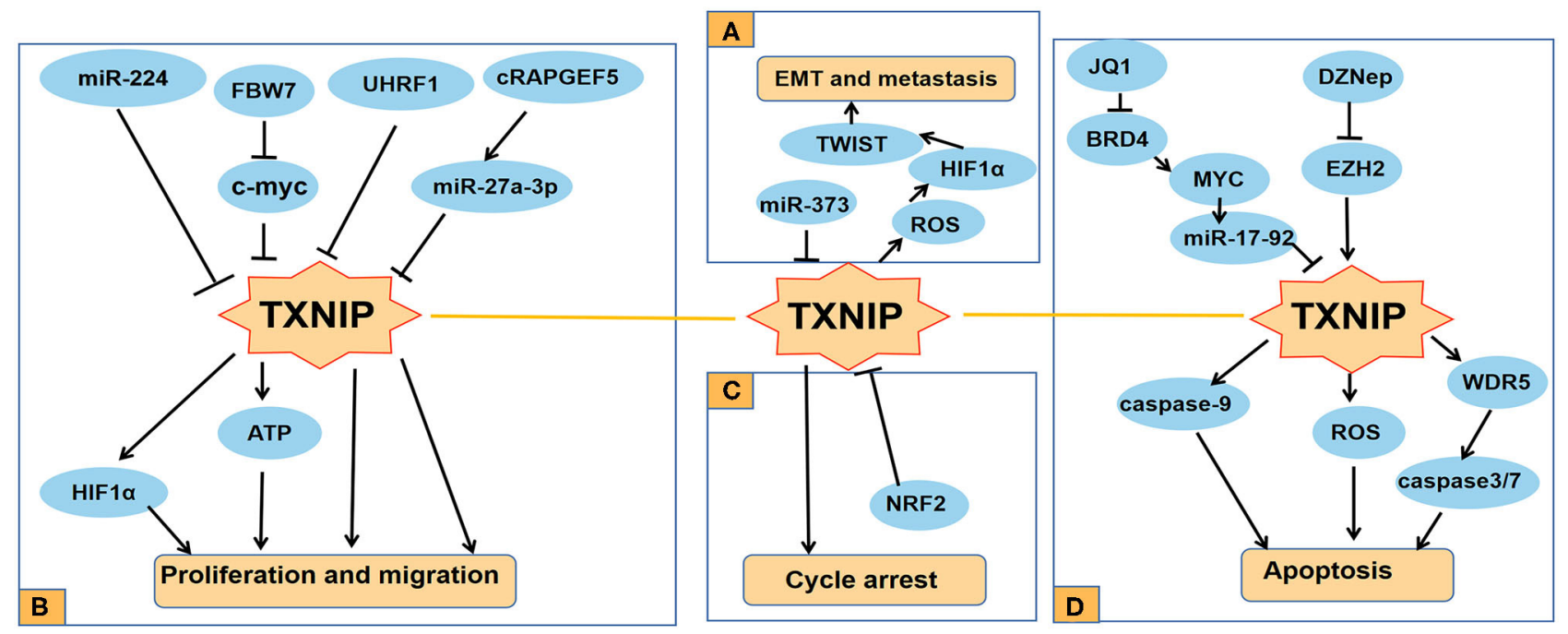

FIGURE 2 | Functions of TXNIP involved in several typical cancers. (A) TXNIP participates in different signaling pathways to inhibit the proliferation and migration of PDAC, RC, and other cancer cells; (B) miR-373 drives the transformation and metastasis of breast cancer by the TXNIP/HIF1 $\alpha / T W I S T$ signaling axis; (C) Knocking down NRF2 can promote the cycle arrest of PCA cells by increasing the expression level of TXNIP; (D) TXNIP participates in different signaling pathways to promote the apoptosis of cancer cells such as AML and lung cancer.

and genomics and the continuous progress of research on thyroid cancer, researchers have found that TXNIP is closely related to PTC (42). TXNIP expression is lower in PTC tissues compared to normal thyroid tissue. The low expression levels of TXNIP are also related to the incidence of lymph node metastasis in PTC; however, they are unrelated to the gender or age of patients (17).

\section{TXNIP and Renal Cancer}

Renal cancer $(\mathrm{RC})$ is a type of cancer that originates in the nephron (43). The incidence of renal cell carcinoma (RCC) is also increasing year by year (44). Studies have confirmed that about $20-30 \%$ patients with RC have distant metastasis at the time of primary diagnosis (45). Bioinformatics analyses have shown that the expression of TXNIP in clear cell renal cell carcinoma (CCRCC) is lower than in normal tissues. Furthermore, the prognosis of patients with CCRCC who have low levels of TXNIP expression is worse than that of patients with high TXNIP expression levels. In addition, the Wnt, mitogen-activated protein kinase (MAPK), phosphatidylinositol, and transforming growth factor- $\beta$ (TGF- $\beta$ ) signaling pathways as well as the autophagy signaling pathway may be the key pathways regulated by TXNIP in patients with CCRCC (46). Ubiquitinlike with PHD and Ring Finger Domains 1 (UHRF1) is an important epigenetic regulator that belongs to the UHRF family. In RCC, UHRF1 can recruit histone deacetylase 1 (HDAC1) to the TXNIP promoter (Figure 1c), which decreases TXNIP expression and promotes the occurrence and development of RCC (Figure 2B) (18). It has also been reported that circular RNA (cirRNA) plays a key role in the development of cancer. CirRNA RAPGEF5 (cRAPGEF5) is a circular RNA derived from exons 2-6 of the RAPGEF5 gene. Studies have shown that cRAPGEF5 targets miR-27a-3p to upregulate its expression. miR-27a-3p targets the 3/UTR in TXNIP to downregulate TXNIP expression, thereby promoting the tumor proliferation and migration in RCC (Figure 2B). TXNIP may therefore be a promising prognostic biomarker for RCC (19).

\section{TXNIP and Bladder Cancer}

Bladder cancer (BC) is the most common malignant tumor of the urinary tract (47). About $70 \%$ of patients diagnosed with bladder cancer have non-muscle-infiltrating $\mathrm{BC}$, with the remaining 25-30\% having myometrial-infiltrating BC. The 5-year survival rate for patients with metastatic BC is only about $15 \%$ (48). Although cisplatin-based chemotherapy benefits patients with advanced and metastatic BC in neoadjuvant treatment, the adverse reactions are significant (49). In neoadjuvant tumors, high levels of TXNIP are considered to be an independent marker for improving disease-specific survival (50). In this regard, it has been shown that TXNIP levels are reduced in BC $(51,52)$. TXNIP can also negatively regulate the occurrence of bladder cancer by inhibiting the activation of ERK, which is induced by stromal cellderived factor-1/C-X-C chemokine receptor type 4 signaling (20). This signal transduction pathway could therefore be an effective target for the prevention or treatment of $\mathrm{BC}$.

\section{TXNIP and Prostate Cancer}

Prostate cancer (PCA) is an epithelial malignant tumor which is the second leading cause of cancer-related death in men (53). Patients with early PCA can adopt radical treatment. In contrast, hormone-sensitive patients with advanced PCA are often treated with endocrine therapy, although it is often difficult to achieve a clinical cure. Therefore, finding new therapeutic targets for the treatment of PCA is particularly urgent. Studies have shown that the consumption of glycolytic intermediates leads to a continuous decline in TXNIP expression caused by $1,25(\mathrm{OH})_{2} \mathrm{D}_{3}$ 
in prostate cells, consistent with the activation of AMP-activated protein kinase (AMPK) signaling and the decrease in c-myc expression (54). Metabolic reprogramming induced by the protooncogene c-myc triggers the dependence of cells on exogenous glucose and glutamine. C-myc activates glutaminase 1 (GLS1) and reduces the activity of the transcription factor MondoA to downregulate TXNIP expression, so as to accelerate the proliferation of PCA cells (21). In human PCA cells, increased glucose metabolism dependently or independently induces the transcription of the TXNIP gene and thereby the expression of TXNIP. Glucose-induced TXNIP requires a glucose regulatory system, including the carbohydrate response element-binding protein (ChREBP) and the carbohydrate response element (ChoRE) (55). It has been shown that nuclear factor E2-related factor 2 (NRF2) is often overexpressed in different human cancers and that it is significantly related to a shortened overall survival time, suggesting that NRF2 may be a novel prognostic biomarker (56). It has also been reported that the NRF2 expression is high in PCA and that knocking down NRF2 can promote TXNIP expression by binding to the TXNIP promoter. This can cause cell-cycle arrest in PCA cells, increasing apoptosis and inhibiting the proliferation of tumor cells (Figure 2C) (22).

\section{TXNIP and Cervical Cancer}

Cervical cancer is one of the most common gynecological malignancies (57). The pathogenesis of cervical cancer is a complex process involving multiple factors and steps $(58,59)$. It is therefore important to search for molecular markers and therapeutic targets for the treatment of cervical cancer. Research has shown that TXNIP overexpression inhibits cell proliferation, invasion, and migration in HeLa cells, whereas TXNIP silencing has the opposite effect in c-33a cells. Moreover, MondoA, rather than ChREBP overexpression, can inhibit cell invasion and migration by upregulating TXNIP in HeLa cells (23).

\section{TXNIP and Endometrial Cancer}

Endometrial cancer is the fourth most common cancer among women worldwide (60-62). Most patients have a good prognosis in the early stage of the disease after treatment $(63,64)$. Although the prognosis of early treatment is good, it is still important to find novel therapeutic molecular targets for its treatment. Studies have confirmed that vitamin D3 plays a key role in the prevention and treatment of various cancers (24), and the concentration of vitamin $\mathrm{D}$ in the blood is also considered as a potential prognostic indicator (65-67). It has been shown that vitamin D3 can regulate the levels of ROS in endometrial cancer cells by increasing TXNIP expression resulting in an inhibition of human endometrial cancer cell proliferation. Vitamin D3 may therefore be important in the treatment of endometrial cancer (68).

\section{CANCERS OF THE DIGESTIVE SYSTEM (TABLE 2) \\ TXNIP and Liver Cancer}

Liver cancer is a disease of the digestive system. Primary liver cancer originates from the epithelial or mesenchymal tissue in the liver (76). Some studies have shown that TXNIP expression levels in hepatoma cell lines are low or absent. As discussed earlier, it is known that vitamin D3 can stimulate TXNIP expression, resulting in reduced cell proliferation and increased apoptosis. The expression of TXNIP in hepatocytes can cause oxidative damage. Stimulating the expression of TXNIP through vitamin D3 and other factors can reduce the canceration of chronic survival patients (69). There are two binding sites, for ChoRE-a and ChoRE-b, in the TXNIP promoter. At high sugar concentrations, ChREBP can bind to the upstream promoter region of TXNIP and promote TXNIP expression (Figure 1d). It has been found that heparin influences cell growth, differentiation, invasion, and migration and promotes

TABLE 2 | TXNIP expression in cancers of the digestive system.

\begin{tabular}{|c|c|c|c|c|c|}
\hline Tumor type & $\begin{array}{l}\text { Upstream or } \\
\text { downstream } \\
\text { molecular }\end{array}$ & Significance & $\begin{array}{l}\text { TXNIP } \\
\text { expression }\end{array}$ & Samples & References \\
\hline Liver cancer & Vitamin D3 & $\begin{array}{l}\text { VitaminD3 can increase the expression of TXNIP to inhibit the } \\
\text { proliferation of liver cancer cells }\end{array}$ & Down & Cell lines & (69) \\
\hline Liver cancer & ChREBP & $\begin{array}{l}\text { ChREBP binds to the upstream promoter region of TXNIP and } \\
\text { promote TXNIP's expression }\end{array}$ & Down & $\begin{array}{l}\text { Cell lines, tissue, } \\
\text { animal }\end{array}$ & $(70)$ \\
\hline Liver cancer & $\mathrm{HBx}$ & $\mathrm{X}$ protein promotes the expression of TXNIP & Down & Cell lines, tissue & $(71)$ \\
\hline Liver cancer & ROS & $\begin{array}{l}\text { overexpression of TXNIP inhibits the proliferation of hepatoma cells } \\
\text { by producing of ROS }\end{array}$ & Down & Cell lines, tissue & $(72)$ \\
\hline Pancreatic cancer & miR-224/HIF1 & $\begin{array}{l}\text { miR-224 targets the 3'UTR of TXNIP to promote the proliferation } \\
\text { and migration of PDAC }\end{array}$ & Down & Cell lines, tissue & (73) \\
\hline Pancreatic cancer & Fbw 7 & $\begin{array}{l}\text { FBW7 can inhibit the expression of c-myc in PDAC to inhibit the } \\
\text { occurrence and development of tumor }\end{array}$ & Down & $\begin{array}{l}\text { Cell lines, tissue, } \\
\text { animal }\end{array}$ & $(74)$ \\
\hline Gastric cancer & $\begin{array}{l}\text { TNF- } \alpha, N F-\kappa B \text { and } \\
\text { COX-2 }\end{array}$ & Disrupting cell growth & Down & Cell lines, tissue & $(75)$ \\
\hline
\end{tabular}

ChREBP, the carbohydrate response element binding protein; ROS, Reactive oxygen species; HIF1, hypoxia-inducible factor; Fbw 7, F-box and WD repeat domain-containing7; TNF- $\alpha$, TumorNecrosisFactor- $\alpha$; NF- $\kappa$ B, nuclear factor kappa-B; COX-2, Cyclooxygenase-2. 
the transcription of TXNIP in hepatoma cells by binding to the ChoRE-b site (70). Studies have also shown that chronic hepatitis $B$ virus (HBV) infection is related to the occurrence and development of hepatocellular carcinoma (HCC) (77). It is well-known that HBV-related HCC is a global health problem (78). Studies have found that the hepatitis $\mathrm{B}$ virus $\mathrm{X}$ protein $(\mathrm{HBx})$, which is a multifunctional protein encoded by the $\mathrm{HBx}$ gene, is involved in the metastasis of hepatitis B-related HCC, and since TXNIP overexpression enhances the migration of HepG2 cells, this suggests that HBV-related HCC is mediated by the HBx protein promoting the expression of TXNIP (71). However, it has also been reported that TXNIP overexpression inhibits proliferation and the induction of apoptosis in hepatoma cells by triggering the mitochondrial-mediated production of ROS and activation of the MAPK pathway. It has been suggested that TXNIP could be a new promising drug target for liver cancer (72).

\section{TXNIP and Pancreatic Cancer}

Pancreatic cancer is a type of digestive tract cancer with a high degree of malignancy and is known to be particularly difficult to diagnose and treat. It is therefore urgent to find new effective treatments because of the extremely high mortality rate for the existing chemotherapy (79). It is well-known that miRNAs. which are non-coding small RNAs, can be used as biomarkers for a tumor's prognosis and could potentially be effective for the treatment of a variety of tumors (80-83). Due to a limited choice of treatment methods, pancreatic ductal adenocarcinoma (PDAC) is the main cause of pancreatic cancerspecific deaths (84). In PDAC, miR-224 targets the 3/UTR of TXNIP and downregulates it, leading to the nuclear translocation of HIF $1 \alpha$, which upregulates HIF $1 \alpha$ and in turn promotes the proliferation and migration of PDAC (Figure 2B) (73). Most patients with pancreatic cancer suffer from glucose intolerance or even diabetes. Researchers have shown that the resulting high levels of glucose promote TXNIP expression by activating the p38 MAPK and ERK pathways, thereby promoting tumor development (85). The F-box and WD repeat domain 7 (FBW7) protein is a substrate recognition component of the SKP1-Cul1F-box (SCF) ubiquitin ligase complex. Increased expression levels of FBW7 can inhibit the expression of c-myc in PDAC, and as a result of the decreased $c$-myc levels the activity of the TXNIP promoter is increased and TXNIP protein levels increase (Figure 2B). This results in a reduction in glucose metabolism in tumor cells inhibiting tumor occurrence and development (74). Some researchers have shown that in pancreatic cancer, FBW7 regulates the nucleoside transporter protein (ENT1) at the protein level rather than at the transcriptional level to promote chemosensitivity to gemcitabine and may therefore be a feasible target for improving the efficacy of chemotherapy in pancreatic cancer (86).

\section{TXNIP and Gastroesophageal Cancer}

Esophageal cancer is a common gastrointestinal tumor, and the incidence of esophageal adenocarcinoma (EAC) is increasing year by year (87). Despite great efforts to improve the treatment of esophageal adenocarcinoma, its 5-year survival rate is still
$<20 \%(88,89)$. In EAC, TXNIP has been confirmed to be an independent prognostic factor for distant metastasis-free survival (90). Studies have indicated that TXNIP overexpression can decrease tumor growth in mice. Furthermore, the upregulation of TXNIP, caused by a histone deacetylase inhibitor, can enhance cisplatin-induced apoptosis and DNA damage. Studies have also confirmed that TXNIP overexpression can inhibit the proliferation of esophageal cancer cells and increase the therapeutic sensitivity of cisplatin and other chemotherapy drugs used for the treatment of esophageal cancer (91). The incidence rate of gastric cancer (92) ranks first among malignant tumors in China with the incidence rate in male being about two times higher than that in women $(93,94)$. Gastric cancer has also been found in the areas of the gastric antrum, the gastric curvature, and the anterior and posterior walls (95-97), with most patients having an adenocarcinoma. Knockout of TXNIP can promote the development of gastric cancer induced by Helicobacter pylori in C57BL/6 mice by inhibiting the induction of tumor necrosis factor (TNF- $\alpha$ ), nuclear factor kappa-B (NF$\kappa \mathrm{B})$, and cyclooxygenase-2 (COX-2) (75).

\section{CANCERS OF THE RESPIRATORY SYSTEM AND OTHERS (TABLE 3) TXNIP and Lung Cancer}

Lung cancer is a type of malignant tumor with the fastestgrowing incidence and mortality rates around the world (107). Non-small cell lung cancer (NSCLC) accounts for about 85\% of all types of lung cancer and is usually diagnosed during the disease's progression or metastasis phase, so the 5-year survival rate is extremely low $(108,109)$. For these patients, the treatment strategy is mainly cisplatin (CDDP)-based chemotherapy (110). However, some patients eventually develop resistance to CDDP, which limits its clinical application (111). Therefore, finding new therapeutic targets for lung cancer patients is of great importance. Studies have shown that cisplatin combined with gemcitabine has a coordinative inhibitory effect in cisplatin-resistant cells. In A549 cells, the combination of gemcitabine and cisplatin results in G0/G1 phase arrest and the upregulation of TXNIP. The cytotoxic effect of a TXNIP agonist combined with cisplatin on drug-resistant cells is additive compared to cisplatin alone. Therefore, the increase in TXNIP expression and G0/G1 phase arrest both play key roles in reversing CDDP resistance (112). Researchers have reported that TXNIP is expressed at low levels in NSCLC (113). Yan Li and other researchers have found that hypoxia is a key feature in the tumor microenvironment. Under hypoxic conditions, the level of TXNIP in NSCLC tissues is upregulated, and high expression levels of TXNIP may be a poor prognostic indicator (114). It has been shown that using tyrosine kinase inhibitor (TKIs) to inhibit PI3K/Akt signaling in NSCLC cell lines can lead to a decrease in cell membranelocalized GLUT1, but increases in TXNIP expression in lung cancer tissues (98). Studies have also shown that mTOR and HDAC inhibitors act by converging on the TXNIP antioxidant pathway to co-affect chromatin and transcription, resulting in the death of aggressive neurological malignancies and tumor 
TABLE 3 | TXNIP expression in cancers of the respiratory system and others.

\begin{tabular}{|c|c|c|c|c|c|}
\hline Tumor type & $\begin{array}{l}\text { Upstream or } \\
\text { downstream } \\
\text { molecular }\end{array}$ & Significance & $\begin{array}{l}\text { TXNIP } \\
\text { expression }\end{array}$ & Samples & References \\
\hline Lung cancer & ASK1 & The drug combination can kill mutant non-small cell lung cancer & Down & Cell lines, tissue & (99) \\
\hline Lung cancer & WDR5 & TXNIP increase WDR5 expression to increase lung cell death & Down & Cell lines & $(100)$ \\
\hline Lung cancer & $m i R-411-5 p / 3 p$ & $\begin{array}{l}\text { Overexpression of miR- } 411-5 p / 3 p \text { can inhibit the expression of } \\
\text { SPRY4 and TXNIP to promotes tumor's proliferation and migration }\end{array}$ & Down & Cell lines, tissue & (102) \\
\hline Leukemia & ChREBP & $\begin{array}{l}\text { ChREBP promotes the development of ROS to promote the } \\
\text { occurrence and development of AML }\end{array}$ & Down & Cell lines, tissue & (103) \\
\hline Leukemia & JQ1 & $\begin{array}{l}\text { JQ1 can reduce the expression of myc to activate the } \\
\text { ASK1-MAPK pathway, which leads to the death of AML cells }\end{array}$ & Down & $\begin{array}{l}\text { Cell lines, tissue, } \\
\text { animal }\end{array}$ & $(104)$ \\
\hline
\end{tabular}

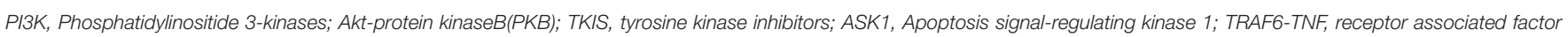
6; JQ1, an Inhibitor of BET bromodomain; PRMT5, protein arginine methyltransferase 5.

shrinkage. The mechanism for this is that TXNIP triggers cell death by inhibiting thioredoxin and activating apoptotic signalregulated kinase 1 (ASK1) signaling. This drug combination can also kill mutant NSCLC and may therefore be important in the treatment of NSCLC (99). Sodium butyrate (NaBu) and sodium 4-phenylbutyrate (4PBA) have broad prospects for the treatment of cancer. In lung cancer cells, TXNIP regulates $\mathrm{NaBu}$ - instead of 4PBA-induced H4K5 acetylation and $\mathrm{H} 3 \mathrm{~K} 4$ trimethylation by increasing the expression of WDR5 after which there is an increase in the activation of caspase 3/7 and cell death (Figure 2D) (100). TNF receptor-related factor 6 (TRAF6) promotes the development of lung cancer by bridging the NF- $\kappa \mathrm{B}$ and RAS pathways. Some researchers have found that $\mathrm{NaBu}$-induced TXNIP can interact with TRAF6 through its PPxY motif, which can cause changes in TXNIP expression and its polyubiquitination, which then affect tumor migration and proliferation in NSCLC (101). Several studies have shown that Dallose, a rare sugar, can inhibit the growth of many malignancies. D-allose can increase TXNIP expression at both protein and mRNA levels, thereby inhibiting the growth of NSCLC (115). The micro RNA miR-411-5p/3p is significantly upregulated in human NSCLC tissues and cell lines, and the overexpression of miR-411$5 \mathrm{p} / 3 \mathrm{p}$ can inhibit the expression of SPRY4 and TXNIP, which in turn promote tumor proliferation and migration, preventing apoptosis in NSCLC cell lines (102).

\section{TXNIP and Leukemia}

Acute myeloid leukemia (AML) is a disease which is characterized by clonal proliferation and is derived from primitive hematopoietic stem cells or progenitor cells. It has an extremely high mortality and poor prognosis in elderly patients $(116,117)$. Cytogenetic analysis revealed that there are a large number of non-random chromosomal abnormalities in AML, with about $60 \%$ of adult AML patients being diagnosed with gene abnormalities (118). TXNIP has been shown to be involved in the reactive oxygen-induced stress responses in mouse leukemia. For example, in screening of new disease genes in mouse leukemia caused by a murine leukemia virus (MLV), TXNIP is found to be a common target for MLV integration. High levels of TXNIP also inhibit the proliferation of myeloid progenitor cells, thereby promoting the occurrence and development of AML and MLV-induced mouse leukemia (119). In AML, the histone methyltransferase inhibitor (DZNep) can increase the levels of TXNIP by clearing the polycomb repressive complex 2 (PRC2) protein and inhibiting the expression of the enhancer of zeste homolog 2 (EZH2) gene, thus inducing ROS generation and leading to apoptosis in AML cells (Figure 2D) (120). Studies have also shown that ChREBP can promote the generation of ROS by downregulating TXNIP expression, thereby promoting the occurrence and development of AML (103). In the process of treating AML, overcoming its drug resistance is a key issue. In AML cells treated with fludarabine (FA), toll-like receptor 4 (TLR 4) or TNF- $\alpha$-mediated activation of the NF-kB signaling pathway can inhibit TXNIP expression, thereby reducing FA-induced cytotoxicity and increasing cell viability (121). Standard therapies for AML rarely achieve a clinical cure (122), and studies have shown that most AML patients do not benefit from existing approved targeted therapies (123). Therefore, finding new therapeutic targets for the treatment of AML is of paramount importance. JQ1 (a BET bromodomain inhibitor) can reduce the expression of $\mathrm{c}$-myc by inhibiting BRD4 (recombinant human bromodomain domain binding protein 4). This reduction in c-myc upregulates TXNIP by inhibiting miR-17-92 and then activates the ASK1-MAPK pathway, which leads to the death of AML cells through the intrinsic apoptotic pathway (Figure 2D) (104). 


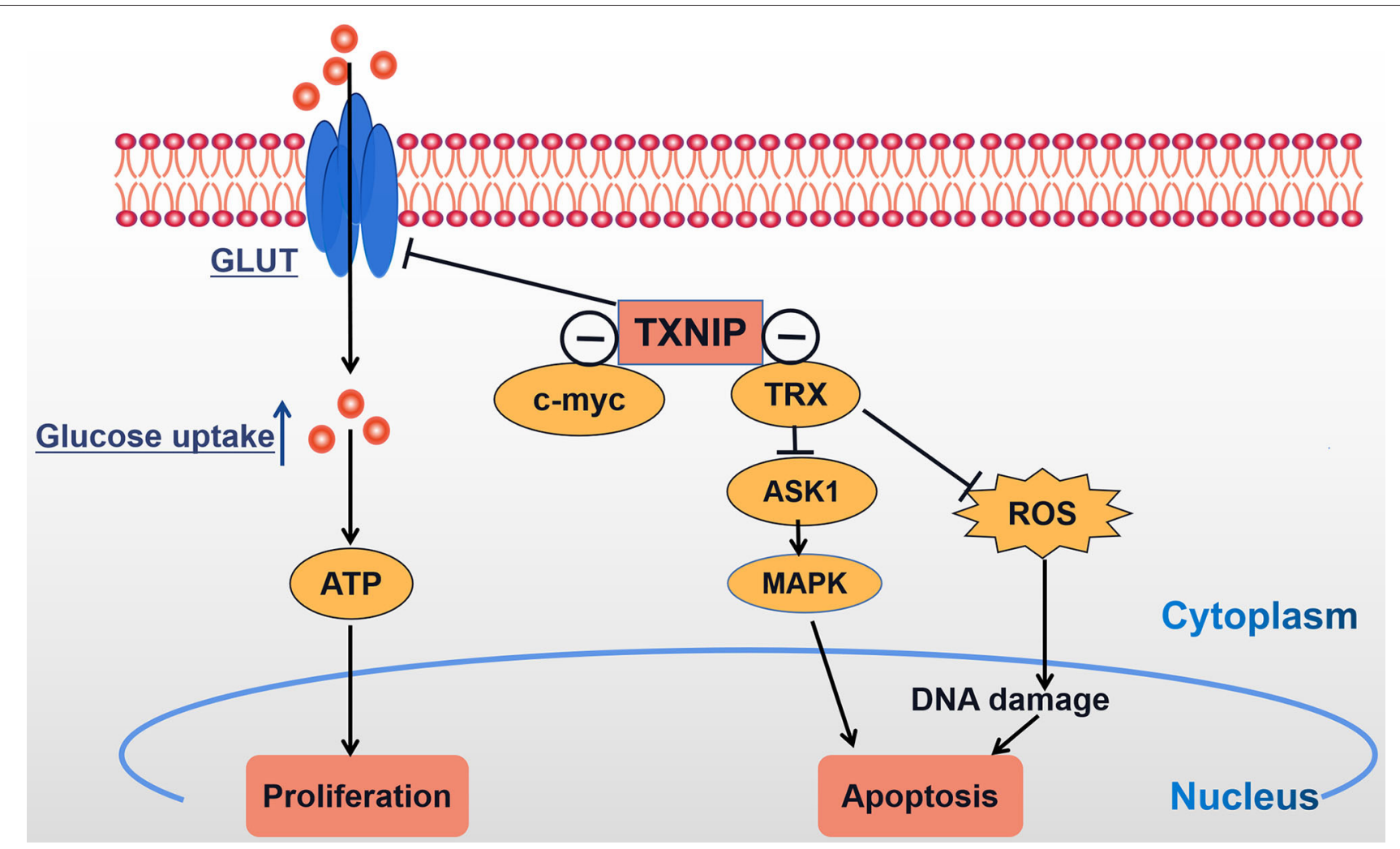

FIGURE 3 | TXNIP acts as a tumor suppressor gene: TXNIP inhibits tumor cell proliferation and promotes tumor cell apoptosis by participating in metabolic reprogramming and oxidative stress; $\ominus$ signs indicate TXNIP-negative interaction.

\section{TXNIP and Osteosarcoma}

Osteosarcoma (OS) is the most common primary malignant bone tumor (124). For patients who are not suitable for surgical treatment, preoperative and postoperative chemotherapy such as CDDP is the standard treatment method. Although neoadjuvant chemotherapy has made significant progress, the prognosis of OS has hardly improved over the past few decades (125). Cell senescence is defined as a permanent state of cell-cycle arrest. A variety of stimuli, such as DNA damage and oxidative stress, have been shown to cause cell senescence $(126,127)$. Importantly, TXNIP has been shown to be another important regulator of cell senescence (128). Researchers have found that protein arginine methyltransferase 5 (PRMT5) is overexpressed in OS and that PRMT5 plays an important role in regulating cell senescence in OS by affecting the repair of DNA damage. Furthermore, TXNIP is a key factor in the DNA damage and cell aging induced by PRMT5 depletion. Targeting the PRMT5/TRIM21/TXNIP signal transduction pathway could provide new therapies for the treatment of OS (105).

\section{TXNIP and Neuroblastoma}

High-risk neuroblastoma (HR-NB) is a disease which is one of the most difficult childhood cancers to cure (129). Fenofibrate has been reported to play an antitumor role in several human cancers. In particular, it has been found that fenofibrate inhibits the proliferation of NB cells, significantly increasing intracellular ROS levels, upregulating TXNIP expression, and promoting cell apoptosis (106). Researchers have also found that estrogen can protect neuroblastoma cells from amyloid- $\beta 42$ (A $\beta 42)$-induced apoptosis through the TXNIP/TRX axis and AMPK signaling pathway (130).

\section{CONCLUSIONS}

With the further study of TXNIP, TXNIP is now expected to become a molecular target for the treatment of different malignancies. TXNIP is expressed at low levels in a variety of malignancies and the overexpression of TXNIP inhibits the proliferation of cancer cells, and so it can be considered as a potential tumor suppressor gene. We conclude that TXNIP acts as a tumor suppressor gene by participating in metabolic reprogramming and oxidative stress (Figure 3). Multiple evidence has shown the abnormal expression and prognostic function of TXNIP in different tumors and illuminated the different molecular mechanisms leading to the acquisition of malignant phenotypes. Given the fact that the morbidity and mortality of cancer in China are continuously rising, seriously threatening people's lives, the prospect of regulating the levels of TXNIP by either genetic means or through drug development gives hope that new tumor treatments can be found. 


\section{AUTHOR CONTRIBUTIONS}

YC is responsible for writing this review. WC, JN, SW, TD, and JJ contributed the same. XF and $\mathrm{BZ}$ are responsible for reviewing and revising. All authors contributed to the article and approved the submitted version.

\section{REFERENCES}

1. Ludwig DL, Kotanides H, Le T, Chavkin D, Bohlen P, Witte L. Cloning, genetic characterization, and chromosomal mapping of the mouse VDUP1 gene. Gene. (2001) 269:103-12. doi: 10.1016/S0378-1119(01)00455-3

2. Nishiyama A, Matsui M, Iwata S, Hirota K, Masutani H, Nakamura H, et al. Identification of thioredoxin-binding protein-2/vitamin $\mathrm{D}(3)$ up-regulated protein 1 as a negative regulator of thioredoxin function and expression. $J$ Biol Chem. (1999) 274:21645-50. doi: 10.1074/jbc.274.31.21645

3. Chung J-W, Jeon J-H, Yoon S-R, Choi I. Vitamin D3 upregulated protein 1 (VDUP1) is a regulator for redox signaling and stress-mediated diseases. Dermatol. (2006) 33:662-9. doi: 10.1111/j.1346-8138.2006.0 0156.x

4. Filhoulaud G, Guilmeau S, Dentin R, Girard J, Postic C. Novel insights into ChREBP regulation and function. Trends Endocrinol Metab. (2013) 24:257-68. doi: 10.1016/j.tem.2013.01.003

5. Lu J, Holmgren A. Thioredoxin system in cell death progression. Antioxid Redox Signal. (2012) 17:1738-47. doi: 10.1089/ars.2012.4650

6. Chen KS, DeLuca HF. Cloning of the human 1 alpha,25-dihydroxyvitamin D-3 24-hydroxylase gene promoter and identification of two vitamin D-responsive elements. Biochim Biophys Acta. (1995) 1263:1-9. doi: 10.1016/0167-4781(95)00060-T

7. Kaimul AM, Nakamura H, Masutani H, Yodoi J. Thioredoxin and thioredoxin-binding protein-2 in cancer and metabolic syndrome. Free Radical Biol Med. (2007) 43:861-8. doi: 10.1016/j.freeradbiomed.2007.05.032

8. Le Bras M, Clément M-V, Pervaiz S, Brenner C. Reactive oxygen species and the mitochondrial signaling pathway of cell death. Histol Histopathol. (2005) 20:205-19. doi: 10.14670/HH-20.205

9. Watanabe R, Nakamura H, Masutani H, Yodoi J. Anti-oxidative, anti-cancer and anti-inflammatory actions by thioredoxin 1 and thioredoxin-binding protein-2. Pharmacol Ther. (2010) 127:261-70. doi: 10.1016/j.pharmthera.2010.04.004

10. Zhou R, Tardivel A, Thorens B, Choi I, Tschopp J. Thioredoxin-interacting protein links oxidative stress to inflammasome activation. Nat Immunol. (2010) 11:136-40. doi: 10.1038/ni.1831

11. Alvarez CE. On the origins of arrestin and rhodopsin. BMC Evol Biol. (2008) 8:222. doi: 10.1186/1471-2148-8-222

12. Liu S, Wu X, Zong M, Tempel W, Loppnau P, Liu Y. Structural basis for a novel interaction between TXNIP and Vav2. FEBS Lett. (2016) 590:857-65. doi: 10.1002/1873-3468.12110

13. Park JW, Lee SH, Woo GH, Kwon HJ, Kim DY. Downregulation of TXNIP leads to high proliferative activity and estrogen-dependent cell growth in breast cancer. Biophys Res Commun. (2018) 498:566-72. doi: 10.1016/j.bbrc.2018.03.020

14. Chen D, Dang Bian-Li, Huang Jin-zhou, Chen Min, Wu Di, Xu Man-Li, et al. MiR-373 drives the epithelial-to-mesenchymal transition and metastasis via the miR-373-TXNIP-HIF1 $\alpha$-TWIST signaling axis in breast cancer. Oncotarget. (2015) 6:32701-12. doi: 10.18632/oncotarge t.4702

15. Shen L, O'Shea JM, Kaadige MR, Cunha S, Wilde BR, Cohen AL, et al. Metabolic reprogramming in triple-negative breast cancer through Myc suppression of TXNIP. Proc Natl Acad Sci USA. (2015) 112:5425-30. doi: 10.1073/pnas.1501555112

16. Morrison JA, Pike LA, Sams SB, Sharma V, Zhou Q, Severson JJ, et al. Thioredoxin interacting protein (TXNIP) is a novel tumor suppressor in thyroid cancer. Mol Cancer. (2014) 13:62. doi: 10.1186/1476-4598-13-62

\section{FUNDING}

This review was funded by the National Natural Science Foundation of China (81372905 to XF), the National Natural Science Foundation of China (81772496), the National Natural Science Foundation of China (82073099), and the Natural Science Foundation of Hunan Province, China (2019JJ40391).

17. Smallridge RC, Copland J. Anaplastic thyroid carcinoma: pathogenesis and emerging therapies. Clin Oncol. (2010) 22:486-97. doi: 10.1016/j.clon.2010.03.013

18. Jiao D, Huan Y, Zheng J, Wei M, Zheng G, Han D, et al. UHRF1 promotes renal cell carcinoma progression through epigenetic regulation of TXNIP. Oncogene. (2019) 38:5686-99. doi: 10.1038/s41388-019-0822-6

19. Chen Q, Liu T, Bao Y, Zhao T, Wang J, Wang H, et al. CircRNA cRAPGEF5 inhibits the growth and metastasis of renal cell carcinoma via the miR-27a-3p/TXNIP pathway. Cancer Lett. (2020) 469:68-77. doi: $10.1016 /$ j.canlet.2019.10.017

20. Nishizawa K, Nishiyama H, Matsui Y, Kobayashi T, Saito R, Kotani H, et al. Thioredoxin-interacting protein suppresses bladder carcinogenesis. Carcinogenesis. (2011) 32:1459-66. doi: 10.1093/carcin/bgr137

21. Qu X, Sun J, Zhang Y, Li J, Hu J, Li K, et al. c-Myc-driven glycolysis via TXNIP suppression is dependent on glutaminase-MondoA axis in prostate cancer. Biochem Biophys Res Commun. (2018) 504:415-21. doi: 10.1016/j.bbrc.2018.08.069

22. Wei M, Jiao D, Han D, Wu J, Wei F, Zheng G, et al. Knockdown of RNF2 induces cell cycle arrest and apoptosis in prostate cancer cells through the upregulation of TXNIP. Oncotarget. (2017) 8:5323-38. doi: 10.18632/oncotarget.14142

23. Zhang J, Tian X, Yin H, Xiao S, Yi S, Zhang Y, et al. TXNIP induced by MondoA, rather than ChREBP, suppresses cervical cancer cell proliferation, migration and invasion. Biochem. (2020) 167:371-7. doi: 10.1093/jb/mvz105

24. Luong K, Nguyen LT. Impact of vitamin D in the treatment of tuberculosis. Am J Med Sci. (2011) 341:493-8. doi: 10.1097/MAJ.0b013e3182070f47

25. Bower JE, Kuhlman KR, Ganz PA, Irwin MR, Crespi CM, Cole SW. Childhood maltreatment and monocyte gene expression among women with breast cancer. Brain Behav Immun. (2020) 88:396-402. doi: 10.1016/j.bbi.2020.04.001

26. Nasoohi S, Ismael S, Ishrat T. Thioredoxin-interacting protein (TXNIP) in cerebrovascular and neurodegenerative diseases: regulation and implication. Mol Neurobiol. (2018) 55:7900-20. doi: 10.1007/s12035-018-0917-z

27. Mahmood DFD, Abderrazak A, El Hadri K, Simmet T, Rouis M. The thioredoxin system as a therapeutic target in human health and disease. Antioxid Redox Signal. (2013) 19:1266-303. doi: 10.1089/ars.2012.4757

28. Christofori G. New signals from the invasive front. Nature. (2006) 441:44450. doi: $10.1038 /$ nature 04872

29. Yang W-H, Lan H-Y, Huang C-H, Tai S-K, Tzeng C-H, Kao S-Y, et al. RAC1 activation mediates twist1-induced cancer cell migration. Nat Cell Biol. (2012) 14:366-74. doi: 10.1038/ncb2455

30. Zhou L, Cha G, Chen L, Yang C, Xu D, Ge M. HIF1 $1 /$ PD-L1 axis mediates hypoxia-induced cell apoptosis and tumor progression in follicular thyroid carcinoma. Onco Targets Ther. (2019) 12:6461-70. doi: 10.2147/OTT.S203724

31. Voorhoeve PM, le Sage C, Schrier M, Gillis AdJM, Stoop H, Nagel $\mathrm{R}$, et al. A genetic screen implicates miRNA-372 and miRNA-373 as oncogenes in testicular germ cell tumors. Cell. (2006) 124:1169-81. doi: 10.1016/j.cell.2006.02.037

32. Huang Q, Gumireddy K, Schrier M, le Sage C, Nagel R, Nair S, et al. The microRNAs miR-373 and miR-520c promote tumour invasion and metastasis. Nat Cell Biol. (2008) 10:202-10. doi: 10.1038/ncb1681

33. Liu P, Wilson MJ. miR-520c and miR-373 upregulate MMP9 expression by targeting mTOR and SIRT1, and activate the Ras/Raf/MEK/Erk signaling pathway and NF-кB factor in human fibrosarcoma cells. J Cell Physiol. (2012) 227:867-76. doi: $10.1002 /$ jcp. 22993 
34. Loayza-Puch F, Yoshida Y, Matsuzaki T, Takahashi C, Kitayama H, Noda M. Hypoxia and RAS-signaling pathways converge on, and cooperatively downregulate, the RECK tumor-suppressor protein through microRNAs. Oncogene. (2010) 29:2638-48. doi: 10.1038/onc.2010.23

35. Gavilanez EL, Litardo NB, Chávez MN, Bonilla MH, Bajaña AS. Thyroid cancer in ecuador. BMC Cancer. (2020) 20:637. doi: 10.1186/s12885-020-07137-0

36. Wang K, Liu CC, Mao AY, Shi JF, Dong P, Huang HY, et al. Analysis on the health literacy of the cancer prevention and treatment and its related factors among urban residents in China from 2015 to 2017. Zhonghua Yu Fang Yi Xue Za Zhi. (2020) 54:76-83. doi: 10.3760/cma.j.issn.0253-9624.2020.01.015

37. Zhang J, Cheng X, Shen L, Wang X, Wang L, Sun X, et al. The association between lymph node stage and clinical prognosis in thyroid cancer. Front Endocrinol. (2020) 11:90. doi: 10.3389/fendo.2020.00090

38. Chen J, Ji Q, Bai Ch, Zheng X, Zhang Y, Shi F, et al. Surufatinib in chinese patients with locally advanced or metastatic differentiated thyroid cancer and medullary thyroid cancer: a multicenter, open-label, phase II trial. Thyroid. (2020) 30:1245-53. doi: 10.1089/thy.2019.0453

39. Hay ID, Lee RA, Davidge-Pitts C, Reading CC, Charboneau JW. Long-term outcome of ultrasound-guided percutaneous ethanol ablation of selected "recurrent" neck nodal metastases in 25 patients with TNM stages III or IVA papillary thyroid carcinoma previously treated by surgery and 131I therapy. Surgery. (2013) 154:1448-4. doi: 10.1016/j.surg.2013.07.007

40. Wei W, Liu Q, Jiang D, Zhao H, Kutyreff CJ, Engle JW, et al. Tissue Factortargeted ImmunoPET imaging and radioimmunotherapy of anaplastic thyroid cancer. Adv Sci. (2020) 7:1903595. doi: 10.1002/advs.201903595

41. Suster D, Michal M, Nishino M, Piana S, Bongiovanni M, Blatnik O, et al. Papillary thyroid carcinoma with prominent myofibroblastic stromal component: clinicopathologic, immunohistochemical and nextgeneration sequencing study of seven cases. Mod Pathol. (2020) 33:1702-11. doi: 10.1038/s41379-020-0539-7

42. Arnér ES, Holmgren A. Physiological functions of thioredoxin and thioredoxin reductase. Eur J Biochem. (2000), 267:6102-9. doi: 10.1046/j.1432-1327.2000.01701.x

43. Shuch B, Amin A, Armstrong AJ, Eble JN, Ficarra V, Lopez-Beltran A, et al. Understanding pathologic variants of renal cell carcinoma: distilling therapeutic opportunities from biologic complexity. Eur Urol. (2015) 67:8597. doi: 10.1016/j.eururo.2014.04.029

44. Bray F, Ferlay J, Soerjomataram I, Siegel RL, Torre LA, Jemal A. Global cancer statistics 2018: GLOBOCAN estimates of incidence and mortality worldwide for 36 cancers in 185 countries. CA Cancer J Clin. (2018) 68:394-424. doi: $10.3322 /$ caac. 21492

45. Dabestani S, Thorstenson A, Lindblad P, Harmenberg U, Ljungberg B, Lundstam S. Renal cell carcinoma recurrences and metastases in primary non-metastatic patients: a population-based study. World J Urol. (2016) 34:1081-6. doi: 10.1007/s00345-016-1773-y

46. Gao Y, Qi J-C, Li X, Sun J-P, Ji H, Li Q-H. Decreased expression of TXNIP predicts poor prognosis in patients with clear cell renal cell carcinoma. Oncol Lett. (2020) 19:763-70. doi: 10.3892/ol.2019.11165

47. Cao R, Ma B, Yuan L, Wang G, Tian Y. Small nucleolar RNAs signature (SNORS) identified clinical outcome and prognosis of bladder cancer (BLCA). Cancer Cell Int. (2020) 20:299. doi: 10.1186/s12935-020-01393-7

48. Mokdad AH, Dwyer-Lindgren L, Fitzmaurice C, Stubbs RW, BertozziVilla A, Morozoff C, et al. Trends and patterns of disparities in cancer mortality among US counties, 1980-2014. JAMA. (2017) 317:388-406. doi: 10.1001/jama.2016.20324

49. Cerbone L, Sternberg CN, Sengeløv L, Agerbaek M, Van Herpen C, Marreaud $\mathrm{S}$, et al. Results from a phase I study of lapatinib with gemcitabine and cisplatin in advanced or metastatic bladder cancer: EORTC trial 30061. Oncology. (2016) 90:21-8. doi: 10.1159/000440959

50. Harb OA, Elsayed Walid SH, Ismail Eman I, Toam Mostafa M, Ammar Mohamed G. Thioredoxin-interact ing-Pro $t \mathrm{e}$ in [TXNIP] and transglutaminase 2 [TGM2] expression in meningiomas of different grades and the role of their expression inmeningioma recurrence and prognosis. Asian Pac J Cancer Prev. (2017) 18:2299-308. doi: 10.22034/APJCP.2017.18.8.2299

51. Holyoake A, O'Sullivan P, Pollock R, Best T, Watanabe J, Kajita Y, et al. Development of a multiplex RNA urine test for the detection and stratification of transitional cell carcinoma of the bladder. Clin Cancer Res. (2008) 14:742-9. doi: 10.1158/1078-0432.CCR-07-1672

52. Ito M, Nishiyama H, Kawanishi H, Matsui S, Guilford P, Reeve A, et al. P21-activated kinase 1: a new molecular marker for intravesical recurrence after transurethral resection of bladder cancer. J Urol. (2007) 178:1073-9. doi: 10.1016/j.juro.2007.05.012

53. Ferlay J, Shin H-R, Bray F, Forman D, Mathers C, Parkin DM. Estimates of worldwide burden of cancer in 2008: GLOBOCAN (2008). Int J Cancer. (2010) 127:2893-917. doi: 10.1002/ijc.25516

54. Abu El Maaty MA, Alborzinia H, Khan SJ, Büttner M, Wölfl S. 1,25(OH)D disrupts glucose metabolism in prostate cancer cells leading to a truncation of the TCA cycle and inhibition of TXNIP expression. Biochim Biophys Acta Mol Cell Res. (2017) 1864:1618-30. doi: 10.1016/j.bbamcr.2017.06.019

55. Qu X, Sun J, Zhang Y, Li J, Hu J, Li K, et al. Thioredoxin-interacting protein: an oxidative stress-related gene is upregulated by glucose in human prostate carcinoma cells. Mol Endocrinol. (2009) 42:205-14. doi: 10.1677/JME-08-0033

56. Li X-D, Chen S-L, Dong P, Chen J-W, Wang F-W, Guo S-J, et al. Overexpression of RNF2 is an independent predictor of outcome in patients with urothelial carcinoma of the bladder undergoing radical cystectomy. Sci Rep. (2016) 6:20894. doi: 10.1038/srep20894

57. Yang T, Xia S. Study of the biological function of LncRNA LUCAT1 on cervical cancer cells by targeting miR-199b-5p. Biosci Rep. (2020) 40:BSR20200422. doi: 10.1042/BSR20200422

58. Zhu L, Zhang Q, Li S, Jiang S, Cui J, Dang G. Interference of the long noncoding RNA CDKN2B-AS1 upregulates miR-181a-5p/TGF $\beta$ I axis to restrain the metastasis and promote apoptosis and senescence of cervical cancer cells. Cancer Med. (2019) 8:1721-30. doi: 10.1002/cam4.2040

59. Guo X-C, Li L, Gao Z-H, Zhou H-W, Li J, Wang Q-Q. The long non-coding RNA PTTG3P promotes growth and metastasis of cervical cancer through PTTG1. Aging. (2019) 11:1333-41. doi: 10.18632/aging.101830

60. Cramer DW. The epidemiology of endometrial and ovarian cancer. Hematol Oncol Clin North Am. (2012) 26:1-12. doi: 10.1016/j.hoc.2011.10.009

61. Lv S, Xu X, Wu Z. Identification of key candidate genes and pathways in endometrial cancer: evidence from bioinformatics analysis. Oncol Lett. (2019) 18:6679-89. doi: 10.3892/ol.2019.11040

62. Siegel RL, Miller KD, Jemal A. Cancer statistics 2018. CA Cancer J Clin. (2018) 68:7-30. doi: 10.3322/caac.21442

63. Sheikh MA, Althouse AD, Freese KE, Soisson S, Edwards RP, Welburn S, et al. USA endometrial cancer projections to 2030: should we be concerned? Future Oncol. (2014) 10:2561-8. doi: 10.2217/fon.14.192

64. Török P, Molnár S, Lampé R, Jakab A. The use of hysteroscopy in endometrial cancer: old questions and novel challenges. Climacteric. (2020). 23:330-5. doi: 10.1080/13697137.2020.1732914

65. Krishnan AV, Trump DL, Johnson CS, Feldman D. The role of vitamin $\mathrm{D}$ in cancer prevention and treatment. Rheum Dis Clin North Am. (2012) 38:161-78. doi: 10.1016/j.rdc.2012.03.014

66. Moukayed M, Grant WB. Molecular link between vitamin D and cancer prevention. Nutrients. (2013) 5:3993-4021. doi: 10.3390/nu5103993

67. Adamczak M, Surma S, Wiecek A. Vitamin D and arterial hypertension: facts and myths. Curr Hypertens Rep. (2020) 22:57. doi: 10.1007/s11906-020-01059-9

68. Kim Y, Kim Y-S, Kim M, Kim J-M, Lee H-H, Kim T-H. Thioredoxininteracting protein (TXNIP) mediates thioredoxin-dependent antioxidant mechanism in endometrial cancer cells treated with $1 \alpha, 25$-dihydroxyvitamin D. Anticancer Res. (2019) 39:4795-803. doi: 10.21873/anticanres. 13664

69. Hamilton JP, Potter JJ, Koganti L, Meltzer SJ, Mezey E. Effects of vitamin D3 stimulation of thioredoxin-interacting protein in hepatocellular carcinoma. Hepatol Res. (2014) 44:1357-66. doi: 10.1111/hepr.12302

70. Gunes A, Iscan E, Topel H, Avci ST, Gumustekin M, Erdal E, et al. Heparin treatment increases thioredoxin interacting protein expression in hepatocellular carcinoma cells. Int J Biochem Cell Biol. (2015) 65:169-81. doi: 10.1016/j.biocel.2015.05.025

71. He Z, Yu Y, Nong Y, Du L, Liu C, Cao Y, et al. Hepatitis B virus X protein promotes hepatocellular carcinoma invasion and metastasis via upregulating thioredoxin interacting protein. Oncol Lett. (2017) 14:1323-32. doi: $10.3892 / \mathrm{ol} .2017 .6296$ 
72. Li J, Yue Z, Xiong W, Sun P, You K, Wang J. TXNIP overexpression suppresses proliferation and induces apoptosis in SMMC7221 cells through ROS generation and MAPK pathway activation. Oncol Rep. (2017) 37:336976. doi: 10.3892/or.2017.5577

73. Zhu G, Zhou L, Liu H, Shan Y, Zhang X. MicroRNA-224 promotes pancreatic cancer cell proliferation and migration by targeting the TXNIPmediated HIF1 $\alpha$ pathway. Cell Physiol Biochem. (2018) 48:1735-46. doi: 10.1159/000492309

74. Ji S, Qin Y, Liang C, Huang R, Shi S, Liu J, et al. FBW7 (F-box and WD repeat domain-containing 7) negatively regulates glucose metabolism by targeting the c-Myc/TXNIP (thioredoxin-binding protein) axis in pancreatic cancer. Clin Cancer Res. (2016) 22:3950-60. doi: 10.1158/1078-0432.CCR-15-2380

75. Lim JY, Yoon SO, Hong SW, Kim JW, Choi SH, Cho JY. Thioredoxin thioredoxin-interacting protein as prognostic markers for gastric cancer recurrence. World J Gastroenterol. (2012) 18:5581-8. doi: 10.3748/wjg.v18.i39.5581

76. Zhang Z, Wang S, Yang F, Meng Z, Liu Y. LncRNA ROR1-AS1 high expression and its prognostic significance in liver cancer. Oncol Rep. (2020) 43:55-74. doi: 10.3892/or.2019.7398

77. Sartorius K, Swadling L, An P, Makarova J, Winkler C, Chuturgoon $\mathrm{A}$, et al. The multiple roles of hepatitis $\mathrm{B}$ virus $\mathrm{X}$ protein $(\mathrm{HBx})$ dysregulated MicroRNA in hepatitis B virus-associated hepatocellular carcinoma (HBV-HCC) and immune pathways. Viruses. (2020) 12:746. doi: $10.3390 / \mathrm{v} 12070746$

78. Roviello G, Casadei-Gardini A, Nobili S, Mini E, Fancelli S. Defining the ideal patient with hepatocellular carcinoma for second-line treatment. J Oncol. (2020) 2020:8024124. doi: 10.1155/2020/8024124

79. Rawat M, Kadian K, Gupta Y, Kumar A, Chain PSG, Kovbasnjuk O, et al. MicroRNA in pancreatic cancer: from biology to therapeutic potential. Genes. (2019) 10:752. doi: 10.3390/genes10100752

80. Daoud AZ, Mulholland EJ, Cole G, McCarthy HO. MicroRNAs in pancreatic cancer: biomarkers, prognostic, and therapeutic modulators. BMC Cancer. (2019) 19:1130. doi: 10.1186/s12885-019-6284-y

81. Zhou B, Sun C, Hu X, Zhan H, Zou H, Feng Y, et al. MicroRNA-195 suppresses the progression of pancreatic cancer by targeting DCLK1. Cell Physiol Biochem. (2017) 44:1867-81. doi: 10.1159/000485876

82. Qian Y, Feng L, Wu W, Weng T, Hu C, Hong B, et al. MicroRNA expression profiling of pancreatic cancer cell line L3.6p1 following B7-H4 knockdown. Cell Physiol Biochem. (2017) 44:494-504. doi: 10.1159/000485086

83. Yang W, Yang Y, Xia L, Yang Y, Wang F, Song M, et al. MiR-221 promotes capan-2 pancreatic ductal adenocarcinoma cells proliferation by targeting PTEN-Akt. Cell Physiol Biochem. (2016) 38:2366-74. doi: 10.1159/000445589

84. Matsumoto K, Takeda Y, Onoyama T, Kawata S, Kurumi H, Koda H, et al. Endoscopic treatment for distal malignant biliary obstruction. Ann Transl Med. (2017) 5:190. doi: 10.21037/atm.2017.02.22

85. Li W, Wu Z, Ma Q, Liu J, Xu Q, Han L, et al. Hyperglycemia regulates TXNIP/TRX/ROS axis via p38 MAPK and ERK pathways in pancreatic cancer. Curr Cancer Drug Targets. (2014) 14:348-56. doi: 10.2174/1568009614666140331231658

86. Hu Q, Qin Y, Zhang B, Liang C, Ji S, Shi S, et al. FBW7 increases the chemosensitivity of pancreatic cancer cells to gemcitabine through upregulation of ENT1. Oncol Rep. (2017) 38:2069-77. doi: 10.3892/or.2017.5856

87. Hur C, Miller M, Kong CY, Dowling EC, Nattinger KJ, Dunn M, et al. Trends in esophageal adenocarcinoma incidence and mortality. Cancer. (2013) 119:1149-58. doi: 10.1002/cncr.27834

88. van Hagen P, Hulshof MCCM, van Lanschot JJB, Steyerberg EW, van Berge Henegouwen MI, Wijnhoven BPL, et al. Preoperative chemoradiotherapy for esophageal or junctional cancer. J Med Imag Radiat Oncol. (2012) 43:215-9. doi: 10.1056/NEJMoa1112088

89. Ferlay J, Colombet M, Soerjomataram I, Mathers C, Parkin DM, Piñeros $\mathrm{M}$, et al. Estimating the global cancer incidence and mortality in 2018: GLOBOCAN sources and methods. Int J Cancer. (2019) 144:1941-53. doi: 10.1002/ijc.31937

90. Woolston CM, Madhusudan S, Soomro IN, Lobo DN, Reece-Smith AM, Parsons SL. Thioredoxin interacting protein and its association with clinical outcome in gastro-oesophageal adenocarcinoma. Redox Biol. (2013) 1:28591. doi: 10.1016/j.redox.2013.04.006
91. Feingold PL, Surman DR, Brown K, Xu Y, McDuffie LA, Shukla V, et al. Induction of thioredoxin-interacting protein by a histone deacetylase inhibitor, entinostat, is associated with DNA damage and apoptosis in esophageal adenocarcinoma. Mol Cancer Ther. (2018) 17:2013-23. doi: 10.1158/1535-7163.MCT-17-1240

92. Yang R, Chang Q, Meng X, Gao N, Wang W. Prognostic value of systemic immune-inflammation index in cancer: a meta-analysis. J Cancer. (2018) 9:3295-302. doi: 10.7150/jca.25691

93. Rao M, Zhu Y, Zhou Y, Cong X, Feng L. MicroRNA-122 inhibits proliferation and invasion in gastric cancer by targeting CREB1. Am J Cancer Res. (2017) 7:323-33.

94. Feng A, Yuan X, Li X. MicroRNA-345 inhibits metastasis and epithelialmesenchymal transition of gastric cancer by targeting FOXQ1. Oncol Rep. (2017) 38:2752-60. doi: 10.3892/or.2017.6001

95. Gao P, Wang S, Jing F, Zhan J, Wang Y. microRNA-203 suppresses invasion of gastric cancer cells by targeting ERK1/2/Slug/ E-cadherin signaling. Cancer Biomark. (2017) 19:11-20. doi: 10.3233/CBM-160167

96. You H-Y, Xie X-M, Zhang W-J, Zhu H-L, Jiang F-Z. Berberine modulates cisplatin sensitivity of human gastric cancer cells by upregulation of miR-203. In Vitro Cell Dev Biol Anim. (2016). 52:857-63. doi: 10.1007/s11626-016-0044-y

97. Sha M, Ye J, Luan Z-Y, Guo T, Wang B, Huang J-X. Celastrol induces cell cycle arrest by MicroRNA-21-mTOR-mediated inhibition p27 protein degradation in gastric cancer. Cancer Cell Int. (2015) 15:101. doi: 10.1186/s12935-015-0256-3

98. Hong SY, Yu F-X, Luo Y, Hagen T. Oncogenic activation of the PI3K/Akt pathway promotes cellular glucose uptake by downregulating the expression of thioredoxin-interacting protein. Cell Signal. (2016) 28:377-83. doi: 10.1016/j.cellsig.2016.01.011

99. Malone CF, Emerson C, Ingraham R, Barbosa W, Guerra S, Yoon H, et al. mTOR and HDAC inhibitors converge on the TXNIP/thioredoxin pathway to cause catastrophic oxidative stress and regression of RAS-driven tumors. Cancer Discov. (2017) 2017:CD-17-0177. doi: 10.1158/2159-8290.CD-17-0177

100. Jin X, Wu N, Dai J, Li Q, Xiao X. TXNIP mediates the differential responses of A549 cells to sodium butyrate and sodium 4-phenylbutyrate treatment. Cancer Med. (2017) 6:424-38. doi: 10.1002/cam4.977

101. Xiao X, Xu Y, Chen H. Sodium butyrate-activated TRAF6-TXNIP pathway affects A549 cells proliferation and migration. Cancer Med. (2020) 9:347788. doi: 10.1002/cam4.2564

102. Zhang C, Wang H, Liu X, Hu Y, Ding L, Zhang X, et al. Oncogenic microRNA-411 promotes lung carcinogenesis by directly targeting suppressor genes SPRY4 and TXNIP. Oncogene. (2018) 38:1892-904. doi: 10.1038/s41388-018-0534-3

103. Zeng $\mathrm{H}, \mathrm{Gu} \mathrm{H}$, Chen $\mathrm{C}$, Li M, Xia F, Xie L, et al. ChREBP promotes the differentiation of leukemia-initiating cells to inhibit leukemogenesis through the TXNIP/RUNX1 pathways. Oncotarget. (2016) 7:38347-58. doi: 10.18632/oncotarget.9520

104. Zhou Y, Zhou J, Lu X, Tan T-Z, Chng W-J. BET bromodomain inhibition promotes De-repression of TXNIP and activation of ASK1MAPK pathway in acute myeloid leukemia. BMC Cancer. (2018) 18:731. doi: 10.1186/s12885-018-4661-6

105. Li Y-H, Tong K-L, Lu J-L, Lin J-B, Li Z-Y, Sang Y, et al. PRMT5-TRIM21 interaction regulates the senescence of osteosarcoma cells by targeting the TXNIP/p21 axis. Aging. (2020) 12:2507-29. doi: 10.18632/aging.102760

106. Su C, Shi A, Cao G, Tao T, Chen R, Hu Z, et al. Fenofibrate suppressed proliferation and migration of human neuroblastoma cells via oxidative stress dependent of TXNIP upregulation. Biochem Biophys Res Commun. (2015) 460:983-8. doi: 10.1016/j.bbrc.2015.03.138

107. Henley SJ, Ward EM, Scott S, Ma J, Anderson RN, Firth AU, et al. Annual report to the nation on the status of cancer, part I: National Cancer Statistics. Cancer. (2020) 126:2225-49. doi: 10.1002/cncr.32802

108. Hamilton G, Rath B. Pharmacogenetics of platinum-based chemotherapy in non-small cell lung cancer: predictive validity of polymorphisms of ERCC1. Expert Opin Drug Metab Toxicol. (2017) 14:17-24. doi: 10.1080/17425255.2018.1416095

109. Cherni I, Weiss GJ. miRNAs in lung cancer: large roles for small players. Future Oncol. (2011) 7:1045-55. doi: 10.2217/fon.11.74 
110. Mezquita L, Jové M, Nadal E, Kfoury M, Morán T, Ricordel C, et al. High prevalence of somatic oncogenic driver alterations in patients with NSCLC and Li-fraumeni syndrome. J Thorac Oncol. (2020) 15:1232-9. doi: $10.1016 /$ j.jtho.2020.03.005

111. Ghosh S. Cisplatin: the first metal based anticancer drug. Bioorg Chem. (2019) 88:102925. doi: 10.1016/j.bioorg.2019.102925

112. Cao W, Yang Q, Yuan Z, Li H, Wang W, Xiao X, et al. Gemcitabine inhibits cisplatin resistance in cisplatin-resistant A549 cells by upregulating trx-interacting protein and inducing cell cycle arrest. Biochem Biophys Res Commun. (2020) 524:549-54. doi: 10.1016/j.bbrc.2020.01.130

113. Kopantzev EP, Monastyrskaya GS, Vinogradova TV, Zinovyeva MV, Kostina $\mathrm{MB}$, Filyukova OB. Differences in gene expression levels between early and later stages of human lung development are opposite to those between normal lung tissue and non-small lung cell carcinoma. Lung Cancer. (2008) 62:23-34. doi: 10.1016/j.lungcan.2008.02.011

114. Li Y, Miao L-Y, Xiao Y-L, Huang M, Yu M, Meng K, et al. Hypoxia induced high expression of thioredoxin interacting protein (TXNIP) in non-small cell lung cancer and its prognostic effect. Asian Pac J Cancer Prev Apjcp. (2015) 16:2953-8. doi: 10.7314/APJCP.2015.16.7.2953

115. Kanaji N, Kamitori K, Hossain A, Noguchi C, Katagi A, Kadowaki $\mathrm{N}$, et al. Additive antitumour effect of dallose in combination with cisplatin in non-small cell lung cancer cells. Oncol Rep. (2018) 39:1292-8. doi: 10.3892/or.2018.6192

116. Wu J, Xiao Y, Jie S, Huiyu S, Chen H, Zhu Y, et al. A single-cell survey of cellular hierarchy in acute myeloid leukemia. J Hematol Oncol. (2020) 13:128. doi: 10.1186/s13045-020-00941-y

117. Arthur C, Jeffrey A, Yip E, Katsioulas V, Nalpantidis A, Kerridge I, et al. Prolonged administration of low-dose cytarabine and thioguanine in elderly patients with acute myeloid leukaemia (AML) achieves high complete remission rates and prolonged survival. Leuk Lymphoma. (2020) 61:831-9. doi: 10.1080/10428194.2019.1697876

118. Kirtonia A, Pandya G, Sethi G, Pandey AK, Das Bhudev C, Garg M. A comprehensive review of genetic alterations and molecular targeted therapies for the implementation of personalized medicine in acute myeloid leukemia. J Mol Med. 98:1069-91. doi: 10.1007/s00109-020-01944-5

119. Erkeland SJ, Palande KK, Valkhof M. The gene encoding thioredoxininteracting protein (TXNIP) is a frequent virus integration site in virusinduced mouse leukemia and is overexpressed in a subset of AML patients. Leuk Res. (2009) 33:1367-71. doi: 10.1016/j.leukres.2009.02.027

120. Zhou J, Bi C, Cheong L-L, Mahara S, Liu S-C, Tay K-G, et al. The histone methyltransferase inhibitor, DZNep, up-regulates TXNIP, increases ROS production, and targets leukemia cells in AML. Blood. (2011) 118:2830-9. doi: 10.1182/blood-2010-07-294827

121. Huy H, Kim T-D, Kim WS, Kim DO, Byun J-E, Kim MJ, et al. TLR4/NF$\kappa \mathrm{B}$ axis induces fludarabine resistance by suppressing TXNIP expression in acute myeloid leukemia cells. Biochem Biophys Res Commun. (2018) 506:33-40. doi: 10.1016/j.bbrc.2018.10.047

122. Wang X, Nachliely M, Harrison JS, Danilenko M, Studzinski GP. Participation of vitamin D-upregulated protein 1 (TXNIP)-ASK1-JNK1 signalosome in the enhancement of AML cell death by a post-cytotoxic differentiation regimen. Steroid Biochem Mol Biol. (2019) 187:166-73. doi: 10.1016/j.jsbmb.2018.11.015

123. Garcia JS, Bhatt S, Fell G, Sperling AS, Burgess M, Keshishian H. Increased mitochondrial apoptotic priming with targeted therapy predicts clinical response to re-induction chemotherapy. Am J Hematol. (2020) 95:245-50. doi: 10.1002/ajh.25692

124. Li B, Ye Z. Epigenetic alterations in osteosarcoma: promising targets. $\mathrm{Mol}$ Biol Rep. (2014) 41:3303-15. doi: 10.1007/s11033-014-3193-7

125. Marina N, Gebhardt M, Teot L, Gorlick R. Biology and therapeutic advances for pediatric osteosarcoma. Oncologist. (2004) 9:422-41. doi: 10.1634/theoncologist.9-4-422

126. de Magalhaes JP, Passos JF. Stress, cell senescence and organismal ageing. Mech Ageing Dev. (2018) 170:2-9. doi: 10.1016/j.mad.2017. 07.001

127. van Deursen JM. The role of senescent cells in ageing. Nature. (2014) 509:439-46. doi: 10.1038/nature13193

128. Devi TS, Hosoya K-I, Terasaki T, Singh LP. Critical role of TXNIP in oxidative stress, DNA damage and retinal pericyte apoptosis under high glucose: implications for diabetic retinopathy. Exp Cell Res. (2013) 319:100112. doi: 10.1016/j.yexcr.2013.01.012

129. Southgate HED, Chen L, Tweddle DA, Curtin NJ. ATR inhibition potentiates PARP inhibitor cytotoxicity in high risk neuroblastoma cell lines by multiple mechanisms. Cancers. (2020) 12:1095. doi: 10.3390/cancers120 51095

130. Pan Q, Guo K, Xue M, Tu Q. Estrogen protects neuroblastoma cell from amyloid- $\beta 42$ (A $\beta 42$ )-induced apoptosis via TXNIP/TRX axis and AMPK signaling. Neurochem Int. (2020) 135:104685. doi: 10.1016/j.neuint.2020.104685

Conflict of Interest: The authors declare that the research was conducted in the absence of any commercial or financial relationships that could be construed as a potential conflict of interest.

Copyright (c) 2020 Chen, Ning, Cao, Wang, Du, Jiang, Feng and Zhang. This is an open-access article distributed under the terms of the Creative Commons Attribution License (CC BY). The use, distribution or reproduction in other forums is permitted, provided the original author(s) and the copyright owner(s) are credited and that the original publication in this journal is cited, in accordance with accepted academic practice. No use, distribution or reproduction is permitted which does not comply with these terms. 